\title{
SÔBRE A OXIDAÇÃO DO ÁCIDO ASCÓRBICO LEVADA A EFEITO EM PRESENÇA DO ION CÚPRICO E SUAS RELAÇÕES COM DETERMINADA CONCENTRAÇÃO DE XANTINA, ANTAGÔNICA DESSA OXIDAÇÃO
}

\author{
Virgilio Bonoldi - Renato F. Ribeiro - O. F. Ribeiro
}

Recentemente GIRI e KRISHNAMURTHy (1) publicaram observações experimentais no tocante à proteção conferida ao ácido ascórbico por uma série de purina-derivados contra a oxidação realizada pelo ar e aquela levada em presença do ion cúprico. Dentre os purinaderivados estudados, destacou-se especialmente a xantina e ácido úrico, derivados purínicos cujo papel naquele sentido, foi total dentro das condições da observação e experiência. Usaram os autores, o manômetro de Warburg, mantendo-se constantes a temperatura $-30^{\circ} \mathrm{C}-$, o pH - 7,2 —, a concentração da solução de ácido ascórbico e ion cúprico (2 mg e 0,71 gamas respectivamente), variando tão sòmente as quantidades dos derivados purínicos ou correlatos empregadas. Deve-se destacar a êste propósito que justamente estavam em menor quantidade presentes, seja a xantina $(0,00017 \mathrm{M})$, seja o ácido úrico (0,00015 M) que inhibiram, uma ou outro, segundo o observaram aqueles autores, totalmente a oxidação do ácido ascórbico, enquanto outros purina-derivados orçaram sua concentração em cerca 4-5 vêzes mais, sem todavia, mesmo assim, protegerem o ácido ascórbico da influência oxidante resultante da presença do ion cúprico.

A leitura dessa contribuição sugeriu-nos verificar qual seria em outras condições de experimentação, êsse comportamento antagônico àquela oxidação e exercido pelas citadas substâncias, o que se procedeu como preliminar e complemento à proteção do ácido ascórbico "in vitro" pela xantina (2).

Em nosso trabalho propuzemo-nos esclarecer o comportamento daqueles purina-derivados, ou melhor, especialmente o da xantina, adotando as seguintes condições de experiência:

$1^{\circ}{ }^{\circ}$ A temperatura ao envés de $30^{\circ} \mathrm{C}$, foi de $40^{\circ} \mathrm{C}$, escolhida pelo fato de se ter maior atividade química das substâncias reagentes;

2..$^{\circ}$ O tempo foi dilatado para 45 minutos, o que permitiria interpretação mais significativa dos resultados; 
$\left.3 .^{\circ}\right)$ Variou-se a concentração do ácido ascórbico e mantiveram-se constantes as concentrações das outras substâncias;

$4 .^{\circ}$ ) Realizou-se em seguida, tendo-se em vista o resultado obtido com essas variações de concentrações do ácido ascórbico, semelhantemente, para o ion cúprico, diluições diversas;

$5^{\circ}{ }^{\circ}$ ) Considerados os resultados obtidos quer pelo emprêgo de diferentes quantidades de ácido ascórbico, quer pelo emprêgo de diferente quantidade de ion cúprico, estabelceu-se o comportamento das substâncias reagentes em tampões aceto-acético e fosfo-fosfórico.

Como se depreende dos intens acima, à xantina não se deu, como às outras substâncias consideradas, variabilidade de concentração. Em última instância, pois, nosso trabalho foi indagar da maneira como se portaria o ácido ascórbico à oxidação, nêste ou naquele $p H$, em presença do ion cúprico, ambos em relações quantitativamente variáveis, em função de concentração fixa de xantina, em um certo lapso de tempo e a dada temperatura. Tanto a solução de xantina empregada pelos autores, como igualmente a solução realizada por nós, estavam praticamente saturadas à temperatura ambiente. Com 70 gamas por $\mathrm{cm}^{3}-0,07 \mathrm{~g}$ por litro: 0,00046 $\mathrm{M}$ - fica satisfeita essa solução: é comum ligeira turvação da mesma, na estação de temperatura ambiente baixa, conseqüentemente à formação de minúsculos cristais insolubilizados e em suspensão.

Deve-se esperar, para diluições de solução de xantina, menor atividades no referente à proteção contra a oxidação do ácido ascórbico - constantes os outros fatores - soluções tanto mais concentradas realizando, verosimilmente, atividade tanto mais incisiva nêsse sentido. De qualquer modo, porém, não é senão a priori que assim se afirmaria, sendo de bom aviso de tal nos abstermos na pesquisa. Mas optamos de qualquer maneira pelo uso de solução saturada, por um lado pressupondo sempre que ela assim se comportaria, e por outro, por igualmente assim o terem feito GIRI e KRISHNAMURTHY, autores do trabalho que inspirou o presente. Os resultados serão por outro lado mais concludentes face aos fatos em averiguação. Não é demais lembrar que o emprêgo de soluções saturadas vai efetivamente redundar, por circunstâncias experimentais, numa referência final à atividade de solução semi-saturada de xantina.

Para estimar o ácido ascórbico ainda existente nas soluções a escolha recaiu sôbre o método do 2,6-diclorofenolindofenol, a técnica do qual está descrita em publicação recente feita por RIBEIRo, BONOLDI, RIBEIRO (3). 
Passemos agora às tabelas em que se poderá vêr o comportamento realizado pelas diversas substâncias dentro das condições dos itens anteriormente expendidos.

T A B E L A I

COMPORTAMENTO DE SOLUÇÕES DE ÁCIDO ASCORBICO DE CONCENTRAÇÕES DIVERSAS - 100 a $250 \mathrm{mg} \%$ - EM FACE DA OXIDAÇÃO COADJUVADA PELO ION CÚPRICO E DA PROTEÇÃO CONTRA ELA EXERCIDA PELA XANTINA EM SOLUÇÃO SEMI-SATURADA

Temperatura de $40^{\circ} \mathrm{C}$.

Solução de sulfato de cobre: $1 \mathrm{~cm}^{3}$ contendo 1 gama de ion cúprico.

Solução de xantina contendo por $\mathrm{cm}^{3} 70$ gamas de dioxi-purina.

Solução aceto-acética tampão $0,2 \mathrm{~N}$ : pH 6, segundo WALPOLE.

Solução de ácido ascórbico com poder redutor sôbre o reativo de Tilmans, fator $0,097=10,5 \mathrm{~cm}^{3}$ para cada $\mathrm{cm}^{3}$ dela: $1,018 \mathrm{mg}$ de ácido ascórbico por $\mathrm{cm}^{3}$.

Volume total completado com água a $10 \mathrm{~cm}^{3} \mathrm{em}$ todos os tubos.

\begin{tabular}{|c|c|c|c|c|c|c|c|c|c|c|}
\hline \multirow{3}{*}{$\begin{array}{l}\text { Tubos } \\
\text { N.: }\end{array}$} & \multicolumn{4}{|c|}{$\mathrm{Cm}^{3}$ da solução de: } & \multirow{2}{*}{\multicolumn{3}{|c|}{$\begin{array}{l}\text { Quantidade de } \\
\text { ácido ascórbico em } \mathrm{mg} \\
\text { existente depois de: }\end{array}$}} & \multirow{2}{*}{\multicolumn{3}{|c|}{$\begin{array}{l}\text { Perda por cento de ácido } \\
\text { ascórbico depois de: }\end{array}$}} \\
\hline & \multirow{2}{*}{$\begin{array}{c}\text { Kcido } \\
\text { ascórbico }\end{array}$} & \multirow{2}{*}{$\begin{array}{c}\text { Tam- } \\
\text { pâo }\end{array}$} & \multirow{2}{*}{$\begin{array}{c}\text { Sulfato } \\
\text { de } \\
\text { cobre }\end{array}$} & \multirow{2}{*}{$\begin{array}{l}\text { Xan- } \\
\text { tina }\end{array}$} & & & & & & \\
\hline & & & & & $15 \mathrm{~m}$ & $30 \mathrm{~m}$ & $45 \mathrm{~m}$ & $15 \mathrm{~m}$ & $30 \mathrm{~m}$ & $45 \mathrm{~m}$ \\
\hline & 1 & & & & & & & & & \\
\hline 1 & $1,01 *$ & 1 & - & - & 0,65 & 0,54 & 0,49 & 36 & 47 & 52 \\
\hline 2 & idem & 1 & 1 & - & 0,49 & 0,45 & 0,41 & 51 & 56 & 59 \\
\hline \multirow[t]{2}{*}{3} & idem & 1 & 1 & 5 & 0,78 & 0,61 & 0,57 & 23 & 40 & 44 \\
\hline & 1,5 & & & & & & & & & \\
\hline 4 & $1,52 *$ & 1 & - & - & 0,93 & 0,77 & 0,70 & 39 & 49 & 54 \\
\hline 5 & idem & 1 & 1 & - & 0,76 & 0,68 & 0,61 & 50 & 55 & 60 \\
\hline \multirow[t]{2}{*}{6} & idem & 1 & 1 & 5 & 1,16 & 0,90 & 0,80 & 24 & 41 & 47 \\
\hline & 2 & & & & & & & & & \\
\hline 7 & 2,0 * & 1 & - & - & 1,30 & 1,05 & 0,94 & 36 & 48 & 53 \\
\hline 8 & idem & 1 & - & - & 1,05 & 0,96 & 0,87 & 48 & 52 & 57 \\
\hline \multirow[t]{2}{*}{9} & idem & 1 & 5 & 5 & 1,58 & 1,32 & 1,16 & 22 & 35 & 43 \\
\hline & 2,5 & & & & & & & & & \\
\hline 10 & 2,54 * & 1 & - & - & 1,72 & 1,43 & 1,28 & 32 & 44 & 50 \\
\hline 11 & idem & 1 & 1 & - & 1,38 & 1,25 & 1,13 & 55 & 51 & 56 \\
\hline 12 & idem & 1 & 1 & 5 & 1,82 & 1,62 & 1,49 & 28 & 36 & 41 \\
\hline
\end{tabular}

(*) Referem-se a mg de ácido ascórbico em $10 \mathrm{~cm}^{3}$ da solução.

Como era de esperar houve por parte da xantina evidente papel protetor contra a oxidação exercida em presença do ion cúprico sôbre o ácido ascórbico, sendo que o emprêgo de quantidades variáveis dêste $-1 \mathrm{mg}$ a 2,5 $\mathrm{mg}$ em $10 \mathrm{~cm}^{3}$ - não implicou em seu papel protetor. A equivalência dessa proteção para concentrações diversas de ácido ascórbico permite-nos assim, o uso de soluções de concentrações va- 
riadas, sem que por êste fato haja necessidade de interpretação particular dos resultados obtidos, pelo menos quando os pesos variarem dentro daqueles limites empregados. Aliás, essas quantidades são aquelas que se prestam mais adequadamente para trabalhos dêste gênero, já que se enquadram na segurança proporcionada pelo método empregado na valoração do ácido em questão.

A tabela, porém, não só nos permite essa conclusão, como igualmente esclarece que para a oxidação espontânea ou para aquela concomitante exercida em presença do ion cúprico, a utilização de pesos diversos de ácido ascórbico - pelo menos dentro dos limites e nas condições da experiência - em nada vai afetar o seu já conhecido comportamento em face dessas substâncias. Assim então, podemos concluir a propósito dos dados fornecidos pela tabela I: o comportamento de soluções com 10 a $25 \mathrm{mg} \%$ de ácido ascórbico, em tampão aceto-acético $\mathrm{pH} 6$, face à oxidação espontânea ou à exercida em presença do ion cúprico é o mesmo, sendo a proteção conferida por solução semi-saturada de xantina, contra essas oxidações, equivalente para qualquer dos pesos empregados.

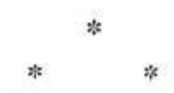

Na tabela II que se segue, estão alinhados os resultados que nos propuzemos no item $4 .^{\circ}$, isto é, dar para o ion cúprico, ao envés do ácido ascórbico, diluições diversas. Como poder-se-á vêr, foram bastante interessantes os resultados coligidos.

A partir da existência de menos de 0,125 gamas de ion cúprico para $10 \mathrm{~cm}^{3}$ da solução na qual estão tambem presentes as outras substâncias reagentes - tubos 11 e 12 - até à diluição mínima dêsse ion (1/128 de gama), empregada nas mesmas condições, seu papel na oxidação do ácido ascórbico não sofre discrepâncias. Apesar de estar presente numa quantidade 100 vezes menor em relação à mais alta concentração, é sempre uniforme, realizando o papel de catalizador cujo rendimento não depende da massa, agindo tão somente pela presença na reação. Assim, na diluição de cerca de 0,008 gamas para os $10 \mathrm{~cm}^{3}$ da solução dos reagentes sua ação é manifesta quanto ao aumento da oxidação do ácido ascórbico relativamente ao exercido pelo ar, mas si manifesta, é, todavia, até a presença de 0,125 gamas sempre a mesma, pelo menos dentro dos limites e nas condições em que foi efetuada a observação. $O$ antagonismo da xantina na concentração utilizada, é total, precisamente, até onde se verifica aquela uniforme ação oxidativa pela presença do ion cúprico, havendo 
V. Bonoldi, R. F. Ribeiro e O. F. Ribeiro - Da proteção do ácido ascórbico 237

proteção de todo o ácido ascórbico empregado. Onde começa a se manifestar uma diminuição do papel protetor da xantina, igualmente o ion cúprico está em maior quantidade, fato esse que se verifica com nitidês quando da existência de um gama de ion cúprico em $10 \mathrm{~cm}^{3}$ do meio reagente. E' esta pois a concentração ideal, ou melhor, gira proximo dela a quantidade mínima limite para a manifestação do efeito do ion cúprico em presença de xantina (protetor), dentro de 15 minutos inicais da observação.

T A B E L A II

COMPORTAMENTO DE SOLUÇõES DE CONCENTRAÇÕES - MENOS DE $\mu \mathrm{g}$ - VARIAVEIS DE ION CÚPRICO EM FACE DE SOLUÇÃO DE ÁCIDO ASCORBICO OXIDAVEL E DE XANTINA SEMI-SATURADA, ANTAGÔNICA DESSA OXIDAÇÃO.

Solução de ácido ascórbico com poder redutor sôbre o reativo de Tilmans, fator $0,097=17$ para cada $\mathrm{cm}^{3} ; 1,649 \mathrm{mg}$ de ácido ascórbico por $\mathrm{cm}^{3}$.

Solução tampão aceto-acética $0,2 \mathrm{~N}, \mathrm{pH}$, segundo WALPoLE.

Solução com quantidades variaveis de ion cúprico. Estabeleceu-se uma série geométrica de diluições razão $2(1 ; 1 / 2 ; 1 / 4 ; 1 / 8 ; 1 / 16 ; 1 / 64 ; 1 / 128)$, contendo assim respectivamente, de ion cúprico, cada $\mathrm{cm}^{3}$ das soluções $1 \mu \mathrm{g} ; 0,5 \mu \mathrm{g} ; 0,25 \mu \mathrm{g} ; 0,125 \mu \mathrm{g} ; 0,0625 \mu \mathrm{g} ; 0,015625 \mu \mathrm{g} ; 0,0078125 \mu \mathrm{g}$.

Volume total completado com água a $10 \mathrm{~cm}^{3} \mathrm{em}$ todos os tubos.

\begin{tabular}{|c|c|c|c|c|c|c|c|c|c|c|}
\hline \multirow{3}{*}{$\begin{array}{l}\text { Tubos } \\
\text { N. }\end{array}$} & \multicolumn{4}{|c|}{$\mathrm{Cm}^{3}$ da solução de: } & \multirow{2}{*}{\multicolumn{3}{|c|}{$\begin{array}{l}\text { Quantidade em } \mathrm{mg} \text { de } \\
\text { aeido ascórbico presentes } \\
\text { em } 10 \mathrm{~cm} 3 \text { depois de: }\end{array}$}} & \multirow{2}{*}{\multicolumn{3}{|c|}{$\begin{array}{l}\text { Conservaçấo por cento em } \\
\text { relação a quantidade de } \\
\text { ácido ascórbico: }\end{array}$}} \\
\hline & \multirow{2}{*}{$\begin{array}{l}\text { Acido } \\
\text { ascér- } \\
\text { bico }\end{array}$} & \multirow{2}{*}{$\begin{array}{c}\text { Tam- } \\
\text { pāo }\end{array}$} & \multirow{2}{*}{$\begin{array}{l}\text { Ion } \\
\text { cúprico }\end{array}$} & \multirow{2}{*}{$\begin{array}{c}X_{\text {an- }} \\
\text { tina }\end{array}$} & & & & & & \\
\hline & & & & & $15 \mathrm{~m}$ & $30 \mathrm{~m}$ & $45 \mathrm{~m}$ & $15 \mathrm{~m}$ & $30 \mathrm{~m}$ & $45 \mathrm{~m}$ \\
\hline 1 & 1 & 1 & - & - & 1,21 & 1,12 & 0,97 & 73,4 & 68,1 & 58,8 \\
\hline 2 & 1 & 1 & $1 / 128$ & - & 1,21 & 1,01 & 0,88 & 73,4 & 61,2 & 53,1 \\
\hline 3 & 1 & 1 & - & 5 & 1,64 & 1,64 & 1,64 & 100 & 100 & 100 \\
\hline 4 & 1 & 1 & $1 / 128$ & 5 & 1,64 & 1,64 & 1,63 & 100 & 100 & 100 \\
\hline 5 & 1 & 1 & $1 / 64$ & - & 1,21 & 1,02 & 0,89 & 73,4 & 62,3 & 54,1 \\
\hline 6 & 1 & 1 & idem & 5 & 1,64 & 1,64 & 1,64 & 100 & 100 & 100 \\
\hline 7 & 1 & 1 & $1 / 32$ & - & 1,21 & 1,02 & 0,87 & 73,4 & 62,3 & 52,9 \\
\hline 8 & 1 & 1 & idem & 5 & 1,64 & 1,64 & 1,64 & 100 & 100 & 100 \\
\hline 9 & 1 & 1 & $1 / 16$ & - & 1,21 & 0,99 & 0,89 & 73,4 & 60,5 & 54,0 \\
\hline 10 & 1 & 1 & idem & 5 & 1,64 & 1,64 & 1,64 & 100 & 100 & 100 \\
\hline 11 & 1 & 1 & $1 / 8$ & - & 1,19 & 1,00 & 0,91 & 72,3 & 61,1 & 55,2 \\
\hline 12 & 1 & 1 & idem & 5 & 1,64 & 1,63 & 1,62 & 100 & 99,3 & 98,7 \\
\hline 13 & 1 & 1 & $1 / 4$ & - & 1,12 & 0,98 & 0,88 & 68,1 & 59,9 & 53,0 \\
\hline 14 & 1 & 1 & idem & 5 & 1,64 & 1,62 & 1,5 & 100 & 98,7 & 94,1 \\
\hline 15 & 1 & 1 & $1 / 2$ & - & 1,06 & 0,97 & 0,85 & 64,7 & 58,8 & 51,7 \\
\hline 16 & 1 & 1 & idem & 5 & 1,64 & 1,60 & 1,55 & 100 & 97,0 & 94,1 \\
\hline 17 & 1 & 1 & 1 & - & 0,97 & 0,89 & 0,77 & 58,8 & 54 & 47,2 \\
\hline 18 & 1 & 1 & idem & 5 & 1,61 & 1,53 & 1,44 & 97,6 & 92,9 & 87,6 \\
\hline
\end{tabular}

Assinale-se que estava nessa concentração o ion cúprico quando do estudo das variações das concentrações do ácido ascórbico, confor- 
me resultado computados na tabela I, fato que encarece o valor daqueles resultados por torná-los mais significativos dentro da observação.

Conhecida a atuação do ion cúprico da maneira verificada, ficamos aptos a interpretar os resultados obtidos por GIRI e KRISHNAMURTHY (1) a propósito duma proteção $100 \%$ da vitamina C pela xantina. Os autores usaram para um volume total de $3 \mathrm{~cm}^{3}$ uma concentração de xantina igual a $0,0017 \mathrm{M}, 0,71$ gama de ion cúprico e $2 \mathrm{mg}$ de ácido ascórbico, ou seja, para $10 \mathrm{~cm}^{3}$ da solução teriamos 75,5 gamas de xantina, 2,13 gamas de ion cúprico e $6 \mathrm{mg}$ de ácido ascórbico, enquanto, em contraposição, usámos 350 gamas de xantina, um gama de ion cúprico e $1,6 \mathrm{mg}$ de ácido ascórbico. Realmente, à primeira vista, parece menos plausivel o estabelecimento de uma interrelação entre duas observações efetuadas com quantidades tão diversas das substâncias reagentes, mas é propriamente essa diversidade dos pêsos empregados que permite aduzir certas conclusões.

Já se esclareceu que, dentro de certos limites, em conseqüência da presença de quantidades diferentes de ácido ascórbico não resulta proporcionalidade diferente na oxidação levada a efeito com o auxílio do ion cúprico - conclusão relativa aos dados da tabela I e linhas acima vimos que, apenas um gama de ion cúprico, já manifesta nitido o seu papel e assim as 2,13 gamas deveriam, com mais razão, igualmente efetuá-lo.

Se não importa a quantidade de ácido ascórbico presente, se o uso feito por GIRI e KRISHNAMURTHY de ion cúprico tenderia a tornar mais manifesto seu papel, enquanto, apesar da grande disparidade entre as duas experimentações, a proporção da dioxipurina não implica propriamente com as conclusões que se aduzem das circunstâncias acima apontadas - pelo contrário reforçam-nas. Tal considerando deduz-se que GIRI e KRISHNAMURTHY ao trabalharem com o manômetro de Warburg, num método mais sensível que o utilizado na feitura do presente, encontraram proteção total dada pela xantina ao ácido ascórbico, para a oxidação em presença do ion cúprico, tão sòmente por terem efetuado a experimentação em temperatura inferior $-30^{\circ} \mathrm{C}-$ àquela em que executamos o nosso trabalho $-40^{\circ} \mathrm{C}$.

Em fenômenos da natureza desse que estudamos, não é demais frisar a importância da temperatura, havendo mesmo, às vêzes, aumento imprevisto na velocidade de transformação de uma reação. Era pois, bem plausível, efetuar as observações a temperatura mais elevada que a escolhida pelos autores acima onde teriamos maior atividade das substâncias reagentes, resultando mesmo atividade surpreendente por parte delas. 
Realmente, a temperatura de $40^{\circ} \mathrm{C}$, corresponde ao limite em que é praticável com relativa segurança, trabalhos semelhantes ao presente. Acima dela, $50^{\circ} \mathrm{C}$ por exemplo, a evaporação especialmente tende a falsear, quase sem contrôle, os resultados.

A menor porção de xantina usada pelos referidos autores 77,5 gamas - em relação à utilizada no presente trabalho - 350 gamas - só vem reforçar o que deduzimos quanto ao emprêgo da temperatura de $30^{\circ} \mathrm{C}$ feita por êles, porquanto, é de se esperar a atividade protetora inferior para soluções de menor concentração de xantina, se bem que, como já o dissemos, seja necessário obter prova experimental nêsse sentido.

Como mais adiante se verá, não só os fatos acima apontados têm influência sôbre o resultado obtido, interferindo também a qualidade do tampão e mesmo o $\mathrm{pH}$ do meio.

Da tabela $I I$, porém, conclui-se que para a quantidade de 10 gamas por cento de ion cúprico, num tampão aceto-acético 0,02 $\mathrm{N}$, aos 15 minutos depois de iniciada a oxidação levada sôbre a vitamina $C$, já há mesmo em presença de concentrações médias - relativamente a uma saturação - de xantina antagônica dessa ação, efeito evidente do cumprimento dessa oxidação o que não se observa quando o mesmo estiver a 1 gama por cento, pelo menos dentro dos limites em que foi efetuada a observação - 45 minutos. Deduz-se mais que é êsse o pêso - e para menores quantidades até um centésimo dêle - a partir do qual se observa uma oxidação constante na proporção do ácido ascórbico o que comprova o papel catalítico atribuido para o ion cúprico a êsse proposito.

Passemos ao comportamento das substâncias reagentes com tampão aceto-acético e pelo fosfo-fosfórico escalonados.

Como vemos, não é indiferente à concentração dos hidrogeniões, quer a oxidação quer a proteção levada sôbre o ácido ascórbico, nas condições da experiência. Não é também menos importante a natureza do tampão empregado (Tabela IV).

Em tampão fosfo-fosfórico, a oxidação espontânea é a que se efetua sôbre menor porcentagem do ácido ascórbico, sendo que em pH 6 se observa menor transformação relativamente à quantidade oxidada em $\mathrm{pH} \mathrm{8,} \mathrm{ambas} \mathrm{todavia} \mathrm{maiores} \mathrm{do} \mathrm{que} \mathrm{em} \mathrm{pH} 7$.

A oxidação do ácido coadjuvada pela presença do ion cúprico cresce à medida que se desce do $\mathrm{pH} 8$ para o $\mathrm{pH} 7$ e finalmente atinge o pH 6. Considerando porém termos oxidação espontânea maior em $\mathrm{pH} 8$, resulta então ser nêste $\mathrm{pH}$ aquêle em que o ion cúprico manifesta menor atividade. 
TABELA III

TAMPĀO FOSFO-FOSFÓRICO pH 7 E 8 E SUAS RELAÇŌES COM A OXIDAÇĀO E PROTEÇÃO DO ÁCIDO ASCÓRBICO LEVADAS A EFEITO EM PRESENÇA DO ION CÚPRICO E XANTINA.

Solução fosfo-fosfórica segundo Sörensen $0,2 \mathrm{~N}$ : $\mathrm{pH} 8$ a $18^{\circ} \mathrm{C}$.

Solução fosfo-fosfórica segundo Sörensen $0,2 \mathrm{~N}$ : 7 a $18^{\circ} \mathrm{C}$.

Solução de ácido ascórbico com poder redutor sôbre o reativo de Tilmans, fator $0,097=18,6 \mathrm{~cm}^{3}$ para cada $\mathrm{cm}^{3}: 1,804 \mathrm{mg}$ de ácido ascórbico por $\mathrm{cm}^{3}$.

Solução de xantina com 70 gamas por $\mathrm{cm}^{3}$ da dioxipurina.

Volume completado em todos os tubos a $10 \mathrm{~cm}^{3}$.

\begin{tabular}{|c|c|c|c|c|c|c|c|c|c|c|}
\hline \multirow[t]{3}{*}{$\begin{array}{c}\text { Tubos } \\
\text { N.o }\end{array}$} & \multicolumn{4}{|c|}{$\mathrm{Cm}^{3}$ da solução de: } & \multicolumn{3}{|c|}{$\begin{array}{l}\text { Quantidade em } \mathrm{mg} \text { de } \\
\text { acido ascórbico presente } \\
\text { um cms depois de: }\end{array}$} & \multicolumn{3}{|c|}{$\begin{array}{l}\text { Ferda por cento em } \\
\text { relaçáo a quantidade de } \\
\text { ácido ascóbbico presente } \\
\text { depois de: }\end{array}$} \\
\hline & \multirow{2}{*}{$\begin{array}{l}\text { Aeido } \\
\text { ascér- } \\
\text { bicoo }\end{array}$} & \multirow{2}{*}{$\begin{array}{r}\text { Tampāo } \\
\mathrm{pH} 8\end{array}$} & \multirow{2}{*}{$\begin{array}{c}\text { Sulfato } \\
\text { de } \\
\text { cobre }\end{array}$} & \multirow[t]{2}{*}{ Xantina } & & & & & & \\
\hline & & & & & & & & m & & $80 \mathrm{~m}$ \\
\hline 1 & 1 & 1 & - & - & 1,45 & 1,29 & 1,12 & 19 & 28 & 38 \\
\hline 2 & 1 & 1 & 1 & - & 1,14 & 0,99 & 0,86 & 37 & 45 & 52 \\
\hline 3 & 1 & 1 & - & 5 & 1,72 & 1,58 & 1,54 & 4 & 12 & 15 \\
\hline 4 & 1 & 1 & 1 & 5 & 1,66 & 1,43 & 1,30 & 8 & 20 & 28 \\
\hline & & $\begin{array}{r}\text { Tamps̃o } \\
\mathrm{pH} 7\end{array}$ & & & & & & & & \\
\hline 5 & 1 & 1 & - & - & 1,63 & 1,47 & 1,31 & 9 & 18 & 27 \\
\hline 6 & 1 & 1 & 1 & - & 1,12 & 0,95 & 0,74 & 38 & 47 & 59 \\
\hline 7 & 1 & 1 & - & 5 & 1,72 & 1,71 & 1,66 & 4 & 5 & 8 \\
\hline 8 & 1 & 1 & 1 & 5 & 1,58 & 1,36 & 1,24 & 12 & 24 & 31 \\
\hline
\end{tabular}

Q U A D R O A

TAMPÃO FOSFO-FOSFÓRICO

Perda por cento em relação à quantidade de ácido ascórbico inicialmente presente em:

\begin{tabular}{|c|c|c|c|c|c|c|c|c|c|}
\hline \multicolumn{4}{|c|}{$\begin{array}{c}\text { TAMPÃO } 8\left(^{*}\right) \\
\text { depois de: }\end{array}$} & \multicolumn{3}{|c|}{$\begin{array}{l}\text { TAMPÃO } 7\left({ }^{*}\right) \\
\text { depois de: }\end{array}$} & \multicolumn{3}{|c|}{$\begin{array}{c}\text { TAMPÃO } 6(* *) \\
\text { depois de: }\end{array}$} \\
\hline $15 \mathrm{~m}$ & $\mathrm{~m}$ & $30 \mathrm{~m}$ & $45 \mathrm{~m}$ & $15 \mathrm{~m}$ & $30 \mathrm{~m}$ & $45 \mathrm{~m}$ & $15 \mathrm{~m}$ & $30 \mathrm{~m}$ & $45 \mathrm{~m}$ \\
\hline 1) 1 & 19 & 28 & 38 & 9 & 18 & 27 & 13 & 22 & 03 \\
\hline 2) 3 & 37 & 45 & 25 & 38 & 47 & 59 & 44 & 52 & 64 \\
\hline 3) & 4 & 12 & 15 & 4 & 5 & 8 & 0 & 2 & 3 \\
\hline 4) & 8 & 20 & 28 & 2 & 24 & 31 & 15 & 26 & 37 \\
\hline
\end{tabular}

(*) Dados retirados da tabela III.

(**) Dados retirados da tabela IV.

1) Oridação pelo oxigênio do ar atmosférico, do ácido ascórbico, ou seja, oxidaçāo espontânea.

2) Oxidação espontânea mais aquela consequente a presença do ion cúprico.

3) Contribuição da xantina para a conservação do ácido ascórbico submetido a oxidação espontânea.

4) Xantina e seu efeito antagônico à oxidação do ácido ascórbico em presença do ar atmosférico e ion cúprico. 
Da interrelação dos dados obtidos pela oxidação espontânea e a levada a efeito em presença do ion cúprico, nos $\mathrm{pH} 6$ e 7 , resulta que nêsses $\mathrm{pH}$ êsse ion transforma, proporcionalmente, de maneira sensívelmente igual, o ácido ascórbico.

A xantina tem seu ótimo de ação justamente em $\mathrm{pH}$ 6, conforme se pode deduzir da análise dos dados: ela aí manifesta o máximo de sua atividade protetora, mais frisante pelo fato de se ter nêsse pH uma oxidação espontânea maior do que a observada em $\mathrm{pH}$ 7. Tanto para êste $\mathrm{pH}$ como para o $\mathrm{pH} 8$, porém, resultou proporcional àquela oxidação espontânea o efeito antagônico da xantina. Nesta ação, em presença do ion cúprico, e da mesma maneira que êste faculta a transformação de maiores proporções de ácido ascórbico à medida que desce o $\mathrm{pH}$, deixa a dioxipurina escapar do seu contrôle, nos diversos graus do $\mathrm{pH}$, igualmente, quantidade cada vez mais pronunciada de ácido ascórbico.

Essa observação dos dados experimentais ilustra, quer-nos parecer, que o papel antagônico observado para a xantina, quando a oxidação do ácido ascórbico é coadjuvada pela presença do ion cúprico, ela não o cumpre amparando o ácido diretamente, mediante combinação, por exemplo, mas sim, implicaria numa ação direta sôbre êsse ion cúprico.

Da correlação geral dos dados referentes ao comportamento das diversas substâncias em exame, em tampões fosfo-fosfórico, salvo experimentação sob outras condições, resulta ser no $p H 6$ que a xantina exerce preponderantemente seu papel antagônico à oxidaçāo que se efetua sôbre o ácido ascórbico.

Isto é evidente se nos lembrarmos que, além de combater a ação ocasionada pela presença do ion cúprico, a xantina diminui, nêsse $\mathrm{pH}$, de tal maneira a oxidação espontânea, que poderiamos quase diretamente deduzir das perdas por cento relativas ao consumo dêsse ácido à oxidação, a proporção de sua proteção. Aliás, pode-se também verificar, das correlações dêsses dados atinentes ao tampão fosfo-fosfórico, que não há interferência do ion cúprico sôbre o exercício da oxiçaçāo espontânea.

Já, a intereferência da natureza do tampão, ressalta evidente ao simples exame da tabela IV. E' mesmo tão patente que nos desobrigamos de maiores comentários.

Relativamente à oxidação espontânea vê-se que a mesma se acha exaitada em tampão aceto-acético 6, isto é, examinando-a quanto à oxidação que ocorre em tampão fosfo-fosfórico, com a mesma concentração de hidrogeniões. O inverso, porém, se dá com a oxidação 
conseqüente à presença do ion cúprico: se em tampão aceto-acético observa-se à oxidação espontânea maior perda de ácido ascórbico, em ambos os tampões 6, porém, de natureza diferente e nos quais há a atuação do ion cúprico, a proporção do ácido ascórbico final é sensìvelmente a mesma. Tem-se então que êsse ion cúprico, em tampão aceto-acético 6 e relativamente a tampão fosfo-fosfórico também 6 , exerce trabalho equivalente.

\section{T A B E L A IV}

TAMPÕES FOSFO-FOSFORICO E ACETO-ACÉTICO, pH 6 E SUAS RELAÇÕES COM A OXIDAÇÃO E PROTEÇÃO DO ÁCIDO ASCÓRBICO LEVADAS A EFEITO EM PRESENÇA DO ION CÛPRICO E XANTINA

Solução fosfo-fosfórica segundo SöRENSEN $0,2 \mathrm{~N}: \mathrm{pH} 6$ a $18^{\circ} \mathrm{C}$.

Solução aceto-acética segundo WALPOLE $0,2 \mathrm{~N}$ : $\mathrm{pH} 6$ a $18^{\circ} \mathrm{C}$.

Solução de ácido acético com poder redutor sôbre o reativo de Tilmans, fator $0,097=17,9 \mathrm{~cm}^{3} ; 1,736 \mathrm{mg}$ de ácido ascórbico por $\mathrm{cm}^{3}$.

Solução de xantina com 70 gamas por $\mathrm{cm}^{3}$ da dioxipurina.

Solução de sulfato de cobre: $1 \mathrm{~cm}^{3}$ contendo um gama de ion cúprico.

Volume completado em todos os tubos a $10 \mathrm{~cm}^{3}$.

\begin{tabular}{|c|c|c|c|c|c|c|c|c|c|c|}
\hline \multirow{3}{*}{$\begin{array}{l}\text { Tubos } \\
\text { N. }\end{array}$} & \multicolumn{4}{|c|}{$\mathrm{Cm}^{3}$ da solução de: } & \multirow{2}{*}{\multicolumn{3}{|c|}{$\begin{array}{l}\text { Quantidade em mg de } \\
\text { ácido ascórbico presente } \\
\text { em um cm3 depois de: }\end{array}$}} & \multirow{2}{*}{\multicolumn{3}{|c|}{$\begin{array}{l}\text { Perda por cento em } \\
\text { relação a quantidade de } \\
\text { ácido ascórbico presente } \\
\text { depois de: }\end{array}$}} \\
\hline & \multirow{2}{*}{$\begin{array}{l}\text { Acido } \\
\text { ascór- } \\
\text { bico }\end{array}$} & \multirow{2}{*}{$\begin{array}{l}\text { Tampão } \\
\text { fosfo-o } \\
\text { fosfórico } \\
\text { pH } 6\end{array}$} & \multirow{2}{*}{$\begin{array}{l}\text { Sulfato } \\
\text { de } \\
\text { cobre }\end{array}$} & \multirow{2}{*}{$\begin{array}{c}\text { Xan- } \\
\text { tina }\end{array}$} & & & & & & \\
\hline & & & & & $15 \mathrm{~m}$ & $30 \mathrm{~m}$ & $45 \mathrm{~m}$ & $15 \mathrm{~m}$ & $30 \mathrm{~m}$ & $45 \mathrm{~m}$ \\
\hline 1 & 1 & 1 & - & - & 1,50 & 1,35 & 1,22 & 13 & 22 & 30 \\
\hline 2 & 1 & 1 & 1 & - & 0,97 & 0,81 & 0,63 & 44 & 53 & 64 \\
\hline 3 & 1 & 1 & - & 5 & 1,72 & 1,69 & 1,68 & 0 & 2 & 3 \\
\hline 4 & 1 & 1 & 1 & 5 & 1,48 & 1,28 & 1,09 & 15 & 26 & 37 \\
\hline & & $\begin{array}{l}\text { Tampão } \\
\text { aceto- } \\
\text { acético } \\
\text { pH } 6 \\
\end{array}$ & & & & & & & & \\
\hline 5 & 1 & 1 & - & - & 1,43 & 1,21 & 0,96 & 17 & 30 & 45 \\
\hline 6 & 1 & 1 & 1 & - & 1,00 & 0,82 & 0,64 & 42 & 53 & 63 \\
\hline 7 & 1 & 1 & - & 5 & 1,71 & 1,69 & 1,67 & 1 & 2 & 4 \\
\hline 8 & 1 & 1 & 1 & 5 & 1,57 & 1,42 & 1,22 & 10 & 18 & 30 \\
\hline
\end{tabular}

Êste fato é de se levar em conta a propósito do efeito protetor da xantina nêsse $\mathrm{pH}$, e para os tampões empregados, quer quando presente o ion cúprico, quer ao estar o ácido ascórbico ùnicamente sob a influência do ar atmosférico. À primeira vista, dir-se-ia o efeito protetor da xantina estar talvez diminuído, mas, se conforme linhas acima aduzimos, essa dioxipurina tem ação direta sôbre o ion cúprico, essa possível diminuição é só aparente. Tendo havido, como há, maior oxidação espontânea e a esta seguindo-se menor, porém diretamente pro- 
porcional, mesmo em presença da xantina, o consumo de ácido ascórbico, conclui-se, funciona de maneira idêntica nos tampões 6 acetoacético e fosfo-fosfórico. Essa conclusão é também corroborada pelo exame, face aos outros, dos resultados obtidos em tampões aceto-acético $\mathrm{pH} 6$ e estando presente tanto a xantina como o ion cúprico.

Permitimo-nos assim, das considerações acima formuladas, concluir que, relativamente à xantina, não há diferença de atuação nas duas variedades de tampões e na concentração usada, aparecendo esta já para a oxidação espontânea no tampão fosfo-fosfórico onde é menor, estando também diminuída a ação catalítica oxidante do ion cúprico, porém, em tampão aceto-acético. Êstes resultados sôbre a interferência da natureza do tampão sôbre o comportamento de substâncias em estudo é de primacial importância, especialmente no caso em aprêço, por ser êste $\mathrm{pH}$ aquêle em que de preferência se trabalha com a ascorbinase, manifestando ela nesta concentração dos hidrogeniões, como sabemos, mais amplamente sua atuação sôbre a vitamina C.

\author{
T A B E L A V
}

TAMPÃO ACETO-ACÉTICO pH 5 E 4 E SUAS RELAÇÕES COM A OXIDAÇÃO E PROTEÇÃO DO ÁCIDO ASCÓRBICO LEVADAS A EFEITO EM PRESENÇA DO ION CÚPRICO E XANTINA

Solução aceto-acética, segundo WALPOLE, pH 5 a $18^{\circ} \mathrm{C}$.

Solução aceto-acética, segundo WALPOLE, pH 4 a $18^{\circ} \mathrm{C}$.

Solução de ácido ascórbico com poder redutor sôbre o reativo de Tilmans, fator $0,097=18,4 \mathrm{~cm}^{3}$ para cada $\mathrm{cm}^{3}: 1,784 \mathrm{mg}$ de ácido ascórbico por $\mathrm{cm}^{3}$.

Solução de xantina com 70 gamas por $\mathrm{cm}^{3}$ da dioxipurina.

Volume completado em todos os tubos a $10 \mathrm{~cm}^{3}$.

\begin{tabular}{|c|c|c|c|c|c|c|c|c|c|c|}
\hline \multirow{3}{*}{$\begin{array}{l}\text { Tubos } \\
\text { N. } .^{\circ}\end{array}$} & \multicolumn{4}{|c|}{$\mathrm{Cm}^{3}$ da solução de: } & \multirow{2}{*}{\multicolumn{3}{|c|}{$\begin{array}{l}\text { Quantidade existente de } \\
\text { áido ascórbico depois de: }\end{array}$}} & \multirow{2}{*}{\multicolumn{3}{|c|}{$\begin{array}{l}\text { Perdas por cento em mg } \\
\text { de acido ascórbico } \\
\text { depois de: }\end{array}$}} \\
\hline & \multirow{2}{*}{$\begin{array}{l}\text { Ácido } \\
\text { ascór- } \\
\text { bico }\end{array}$} & \multirow{2}{*}{$\underset{\mathrm{pH}}{\text { Tampão }}$} & \multirow{2}{*}{$\begin{array}{c}\text { Sulfato } \\
\text { de } \\
\text { cobre }\end{array}$} & \multirow{2}{*}{ Xantina } & & & & & & \\
\hline & & & & & $15 \mathrm{~m}$ & $30 \mathrm{~m}$ & $45 \mathrm{~m}$ & $15 \mathrm{~m}$ & $30 \mathrm{~m}$ & $45 \mathrm{~m}$ \\
\hline 1 & 1 & 1 & 一 & - & 1,10 & 0,87 & 0,69 & 38 & 51 & 61 \\
\hline 2 & 1 & 1 & 1 & - & 1,00 & 0,69 & 0,54 & 45 & 61 & 70 \\
\hline 3 & 1 & 1 & - & 5 & 1,54 & 1,31 & 1,29 & 13 & 17 & 27 \\
\hline \multirow[t]{2}{*}{4} & 1 & 1 & 1 & 5 & 1,26 & 1,03 & 1,83 & 29 & 42 & 53 \\
\hline & & $\underset{\mathrm{pH}}{\operatorname{Tampa} o}$ & & & & . & & & & \\
\hline 5 & 1 & 1 & - & - & 1,47 & 1,31 & 1,16 & 13 & 27 & 35 \\
\hline 6 & 1 & 1 & 1 & - & 1,16 & 0,99 & 0,81 & 35 & 44 & 54 \\
\hline 7 & 1 & 1 & - & 5 & 1,70 & 1,53 & 1,54 & 4 & 12 & 14 \\
\hline 8 & 1 & 1 & 1 & 5 & 1,31 & 1,08 & 0,90 & 27 & 39 & 50 \\
\hline
\end{tabular}


GIRI e KRISHNAMURTHY no seu trabalho não fazem referência à natureza do tampão empregado. Se fica excluída a solução acetoacética, por não atingir tampão da altura do empregado $(\mathrm{pH} 7,2)$, outra que o fosfo-fosfórico não é de se eliminar, apesar de ser mais provável o emprêgo de solução fosfo-fosfórica.

Resta-nos agora, finalmente, comentar as relações que apresenta o tampão aceto-acético em face da proteção e oxidação do ácido ascórbico sob as condições já conhecidas.

\section{Q U A D R O B \\ TAMPÃO ACETO-ACÉTICO}

Perda por cento em relação a quantidade de ácido ascórbico inicialmente presente em:

\begin{tabular}{|c|c|c|c|c|c|c|c|c|}
\hline \multicolumn{3}{|c|}{$\begin{array}{c}\text { TAMPÃO } 6\left({ }^{*}\right) \\
\text { depois de: }\end{array}$} & \multicolumn{3}{|c|}{$\begin{array}{c}\text { TAMPÃO } 5(* *) \\
\text { depois de: }\end{array}$} & \multicolumn{3}{|c|}{$\begin{array}{c}\text { TAMPÃO } 4\left({ }^{* *}\right) \\
\text { depois de: }\end{array}$} \\
\hline $15 \mathrm{~m}$ & $30 \mathrm{~m}$ & $45 \mathrm{~m}$ & $15 \mathrm{~m}$ & $30 \mathrm{~m}$ & $45 \mathrm{~m}$ & $15 \mathrm{~m}$ & $30 \mathrm{~m}$ & $45 \mathrm{~m}$ \\
\hline 1) 17 & 30 & 45 & 38 & 51 & 61 & 13 & 27 & 35 \\
\hline 2) 42 & 53 & 63 & 45 & 61 & 70 & 35 & 44 & 54 \\
\hline 3) 1 & 2 & 4 & 13 & 17 & 27 & 4 & 12 & 14 \\
\hline 4) 10 & 18 & 30 & 29 & 42 & 53 & 27 & 39 & 50 \\
\hline
\end{tabular}

(*) Dados referentes a tabela IV.

(**) Dados referentes a tabela V.

1) Oxidação, pelo oxigênio do ar atmosférico, do ácido ascórbico, ou seja, oxidaçāo espontânea

2) Oxidação espontânea mais aquela consequente a presença do ion cúprico. espontânes.

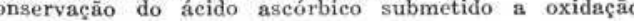

4) Xantina e seu efeito antagônico à oxidaçāo do ácido ascórbico em presença do ar atmosférico e ion cúprico.

Analisando-se os dados correspondentes à oxidação do ácido ascórbico e contribuição da xantina nos três $\mathrm{pH}$ usados é sem dúvida bastante diverso o comportamento.

Dentro porém de cada $\mathrm{pH}$ e relativamente aos outros, o comportamento é semelhante e aplicam-se "mutatis-mutandis" as mesmas conclusões gerais anteriormente aduzidas a propósito, especialmente, da xantina. Esta dioxipurina por exemplo, de maneira análoga ao que ocorre nos tampões fosfo-fosfórico, protege proporcional se bem que diferentemente, o ácido ascórbico, sujeito a oxidação espontânea nos $\mathrm{pH}$ usados. Sua contribuição, quando presente o ion cúprico catalizante daquela oxidação, faz-se independentemente da proteção que se espera da resultante do ar atmosférico, tal qual concluimos a propósito da tabela III.

São estas aliás as mais importantes conclusões, ou seja, em tampões aceto-acético tal como em fosfo-fosfórico, tem-se, se bem em 
proporção diferente, semelhante contribuição da xantina quanto a seu papel antagônico à oxidação ocasionada diretamente pelo ar ou àquela catalizada pelo ion cúprico.

\section{CONCLUSÕES GERAIS}

Dentro do tempo e na temperatura da experiência, isto é, no espaço de 45 minutos e a $40^{\circ} \mathrm{C}$, sendo usado o método Tilmans para valoração, pode-se concluir que à oxidação do ácido ascórbico — levada em presença do ion cúprico - e à proteção a êle dada por soluções semi-saturadas de xantina,

$\left.1^{\circ}\right)$ é indiferente a sua concentração, dentro dos limites usados $-0,1$ a $0,25 \mathrm{~g}$;

$2 .^{\circ}$ ) é, já aos 15 minutos, evidente o papel exercido por êsse ion cúprico, na concentração de $1 \mathrm{mg}$, mesmo estando presente a xantina antagônica da oxidação;

$3 .^{\circ}$ ) é, mesmo para diluições centesimas dessa concentração do ion cúprico, franco o seu papel de catalizador da transformação do ácido ascórbico, havendo todavia nessas condições proteção total por parte da xantina quando ela presente em solução semi-saturada;

$4 .^{\circ}$ ) é de importância, relativamente às quantidades transformadas, quer a natureza do tampão, quer o $\mathrm{pH}$ da solução em que se passa a oxidação e proteção do ácido ascórbico;

$\left.5 .^{\circ}\right)$ é a proteção exercida pela xantina nos diversos $\mathrm{pH}$ de 4 a 8 - seja no que se refere à oxidação pelo oxigênio do ar, seja aquela coadjuvada pelo ion cúprico, proporcional dentro de cada $\mathrm{pH}$, a essas oxidações;

$\left.6 .^{\circ}\right)$ importa, por fim, ter presente certa concentração de ion cúprico - $1 \mathrm{mg}$ cerca — além do que não é indiferente a concentração dos hidrogeniões como igualmente o emprêgo destas ou daquelas substâncias fornecedoras dos tampões.

\section{RESUMO}

A temperatura de $40^{\circ} \mathrm{C}$ e no espaço de 45 minutos, usando soluções semi-saturadas de xantina protetora, os autores indagaram do comportamento de soluções de concentrações variáveis de ácido ascórbico em face da oxidação catalizada pelo ion cúprico — usado igualmente em pêso variável - e empregando tampões aceto-acético e fosfo-fosfórico de concentrações diversas relativamente a hidrogeniões, sendo estimada pelo 2,6-diclorofenol-indofenol a vitamina remanescente. Tendo em vista a correlação geral dos dados fornecidos pela experimentação e nas condições em que a mesma foi efetuada, os autores concluem ser indiferente o pêso utilizado de ácido ascórbico - 
pelo menos estando com quantidade de 0,1 a $0,25 \mathrm{~g}$ por litro. A existência de cêrca de $1 \mathrm{mg}$ por litro de ion cúprico, face a essas concentrações de vitamina, importa, porém, para que se manifeste, logo aos 15 minutos da experiência, seu papel catalizante da oxidação, quando estiver presente a xantina semi-saturada $(0,00023 \mathrm{M})$, antagônica dessa ação.

$\mathrm{O}$ emprêgo de $\mathrm{pH}$ variando entre 4 e 8 , bem como a natureza do tampão quanto às substâncias que o integram, têm influências no exercício de tal oxidação e proteção, implicando por isso, que sejam levados em conta e referidos ao se efetuarem e relatarem experiências como a presentemente considerada.

\section{SUMMARY}

The authors inquired as to the behavior of ascorbic acid solutions of variable concentrations, at the temperature of $40^{\circ} \mathrm{C}$. and in the space of 45 minutes, in face of catalized oxidation by the cupric ion used also in variable weights - employing aceto-acetic and phosphophosphoric buffers of several concentrations in relation to hidrogenions, the remaining vitamin being estimated by the 2,6-dichlorophenolindophenol. Keeping in mind the general correlation of data furnished by the experiment, and under conditions which it was effected, the authors conclude that the weight of ascorbic acid employed is indifferent - at least if it be in the quantity of 0,1 to $0,25 \mathrm{~g}$ per liter. The existence of about $1 \mathrm{mg}$ of cupric ion per liter, in face of such vitamin concentrations, determines, however, that within 15 minutes of the experiment, its catalizing role of oxidation be manifest, when the semi-satured xantina $(0,00023 \mathrm{M})$, antagonic to that action, is present.

The employment of $\mathrm{pH}$ varying between 4 and 8 , as well as the nature of the buffer as to the substances of which it is integrated, have influence in the exercise of such oxidation and protection, thus employing that they must be renunded and referred to when experiments such as the ones presently considered are effected or reported.

BIBLIOGRAFIA

1 - Giri, K. V. and P. V. Krishnamurthy - 1941 - Influences of purines, creatinine and creatine on the oxidation of vitamin C. Nature, 147: 59.

2 - Ribeiro, Fonseca e Virgilio Bonoldi - 1943 - Da proteção do ácido ascórbico "in vitro" pela xantina, substancias correlatas e extrato hepatico total ou não, contra agentes de oxidação. Rev. Fac. Med. Vet., S. Paulo, 2 (3) : 87-97.

3 - Ribeiro, R. F., V. Bonoldi e O. F. Ribeiro - 1942 - Sôbre o tempo de ação do SH2 no doseamento do ácido ascórbico. Rev. Fac. Med. Vet., S. Paulo, 2 (2) : 29-39. 